\title{
An Endowment, Commodity, and Prospect Theory Perspective on Consumer Hoarding Behavior
}

\author{
Diana King $^{1} \&$ Raj Devasagayam ${ }^{2 *}$ \\ ${ }^{1}$ Siena College, Loudonville, NY, USA \\ ${ }^{2}$ Professor of Marketing, Director, Center for Undergraduate Research and Creative Activity Siena \\ College, Loudonville, NY, USA \\ *Raj Devasagayam, E-mail: raj@siena.edu
}

Received: March 10, 2017

Accepted: March 20, 2017

Online Published: April 7, 2017

doi:10.22158/jbtp.v5n2p77

URL: http://dx.doi.org/10.22158/jbtp.v5n2p77

\begin{abstract}
This study investigated the preconditions that drive hoarding behaviors when consumers perceive a shortage in supply and are faced with other marketing stimuli indicating product scarcity. Pat research shows that hoarding behaviors exists due to the acknowledgement of the scarcity of products that previously had been in excess, and consumer response to such scarcity. Endowment Effect, Commodity Theory, and the Prospect Theory were used as the basis for our conceptual framework. Data was obtained from a random sample of 297 individuals and subjected to statistical analyses. Our findings indicated that perceived perishability and scarcity of items that are valued, elicit a reaction in consumers who have an aversion to risk due to the prospect of losing an item of value. Losses were intensified when perceived perishability and scarcity were established through urgency in advertising resulting in higher buying rates. Our findings can help marketing managers acquire more knowledge of purchase motives, satisfaction, and feelings of uniqueness gained through hoarding. Furthermore, once an understanding of what motivates consumers to accelerate their purchase behavior under perceived perishability and scarcity conditions is obtained, pricing and inventory strategies (indeed the entire marketing mix) can be strategically designed to meet the needs of the customer.
\end{abstract}

Keywords

consumer hoarding, endowment effect, commodity theory, prospect theory, empirical findings, marketing strategy, perceived scarcity, perishability

\section{Introduction}

We investigated hoarding behavior among consumers to examine antecedents that lead to hoarding behavior when consumers perceive a shortage in supply. Additionally, we examined their personality traits, lifestyle habits, and how advertising instills an urgent need to purchase items.

Hoarding exists when the consumer's current inventory of an item exceeds the inventory for previous periods while the consumption rate remains the same. Past research shows that the relationship between hoarding and expected consumption is influenced by the anticipated duration of shortages (Stiff, 1975). Additionally, preconditions exist in certain consumer personalities that have greater levels of obsessive compulsive symptoms and indecisiveness. Saving allows control over making the wrong decision to discard possessions that may be needed in the future and avoids the emotional discomfort associated with losing an item that has an emotional attachment associated with it (Frost \& Gross, 1993). Perceived perish ability and scarcity of items that are valued elicit a reaction in consumers who have an 
aversion to risk due to the prospect of losing an item of value. We investigated hoarding behavior and the impact it had on emotional attachment to possession, uncertainty of the future due to urgency in advertising, and the perceived scarcity of items. Losses were intensified when perceived perishability and scarcity were established through urgency in advertising resulting in higher buying rates. We tested the theoretical framework using a random sample $(n=297)$. We discuss the theoretical framework and method used to study hoarding behavior under conditions of perceived perishability and scarcity.

Three dependent variables of hoarding behavior were used: consumers who had difficulty discarding possessions, consumers who had a large percentage of unused items, and those consumers that carried just-in-case items (Canale \& Klontz, 2013). Our findings revealed that uncertainty of future supply, or perceived shortages, have an impact on hoarding behaviors. Consumers with high levels of hoarding behaviors, such as the dependent variables mentioned above, will be sensitive to advertisements that portray uncertainty of future items and will lead to a higher purchase rate. Hoarding is also associated with an emotional attachment to possessions. Consumers attach a value to the item in their possession and once they have it, will find it difficult to do without that item (Frost \& Gross, 1993).

These findings are in agreement with a new retail strategy being used by fast fashion companies which intentionally limit supply and availability causing the consumer to perceive the items are perishable and will be scarce, thus causing in-store hoarding (Byun \& Sternquist, 2008). Perishability refers to items that go out of stock and cannot be purchased anywhere else causing the consumer to accelerate their decision to purchase the item before it becomes obsolete (Bulow, 1986). Perceived scarcity refers to product shortages or limited time offers which motivates an urgency to buy the available items.

\section{Prior Research}

Emotional Attachment: "Possessions are imbued with importance far in excess of their true value" (Frost et al., 1995). Beliefs about possessions, and emotional distress and avoidance result in manifestations of hoarding including acquisition, saving and clutter. Symptoms are defined as saving unless the items contain little or no sentimental value, which is distinguished from items that they find "interesting and valuable". When possessions provide feelings of safety, there are higher levels of emotional attachment (Frost et al., 1995).

Perceived Scarcity: The hoarding consumer will try to reduce their risk of loss when perceived scarcity is present by moving quickly to acquire large quantities of the item. Hoarding is often adopted as a coping strategy to reduce fear or perceived risk of product shortage and purchase goods without regard to their immediate use (Sternquist, 2007). The level of hoarding is related to the uncertainty of future product availability, leading the consumer to evaluate the outcome of their buying or not buying decision (Byun \& Sternquist, 2012).

Perceived Perishability: Retailers are communicating limited availability through a short renewal cycle and deliberate reduction in a product's life span (Bulow, 1986). The retailer introduces new styles weekly and rapidly turns over the product. The consumer reacts to the perceived perishability of a product by running to purchase it before it becomes unavailable.

Advertising: Relating to the means of hoarding itself, advertisements are key to the vulnerability of individuals who hoard, where specific personalities are affected by hoarding differently. Certain personalities will be affected differently when the urgency of situations increase (Frost et al., 1995). In fact, theories of hoarding leads to marketing implications involving distribution pricing, advertising and public relation positions, for "hoarding develops as a result of emotional responses to various thoughts and beliefs" (Canale \& Klontz, 2013). Sociologists place a greater role on mass media and 
interpersonal communications as signals for hoarding, as well as the direct observation of both retail ability and the purchase behavior of other consumers (Stiff, Johnson, \& Tourk, 1975). Understanding advertising's role in hoarding behaviors is essential to establish efficient advertisements based upon findings.

Psychological: Hoarding develops as a result of "conditional emotional responses to various thoughts and beliefs" (Canale \& Klontz, 2013). Hoarders also think about future uncertainties and the chance that the items are needed in the near term (Canale \& Klontz, 2013). Individuals who are hoarders have difficulty discarding items, carry more "just-in-case" items and also carry a large percentage of unused items in order to avoid making the decision to discard them, thus indicating indecisiveness (Coles et al., 2003).

\section{Theoretical Framework}

The theoretical framework that is created by perceived perishability and scarcity explains consumer hoarding behavior and accelerated purchase rates. Expected shortages, uncertainty of the future and the urgency created by advertisements creates a different shopping behavior among consumers. Retailers who create perceived perishability and scarcity produce hoarding behavior responses from consumers since an emotional attachment to an item will stimulate an aversion to losing that item. Endowment Effect, Commodity Theory, and the Prospect Theory are the basis for our conceptual framework. Consumers often demand much more to give up an item than they would be willing to pay to acquire it. Loss aversion - people ascribe more value to things merely because they own them and don't want to give them up-relates to emotional attachment to possessions, evaluated as gains and losses relative to a reference point (Kahneman \& Tversky, 1979).

The Endowment Effect states that people tend to place a higher value on objects they own, or merely possess, rather than objects they don't own. Mere possession of a product increases the sense of endowment and the prospect of losing the item with emotional value increases hoarding behavior and purchase acceleration (Thaler, 1980).

The Commodity Theory explains psychological effects of scarce products and opportunities which are valued more highly (Brock, 1968; Lynn, 1991). It claims that "any commodity will be valued to the extent that it is unavailable" (Brock, 1968). Commodities meet three criteria: usefulness, transferability, and the potential to be possessed. The term "value" refers to the commodity's "potency for affecting attitudes and behavior" thus causing desirability (Brock, 1968; Lynn, 1991). Commodities that are unavailable, or scarce, are desired by the consumer because possessing these items conveys feelings of personal distinctiveness or uniqueness, which adds value.

Prospect Theory (Kahneman \& Tversky, 1979) explains consumer decision making under uncertainty and leads to evaluation of the prospect of acquiring or losing an item. This theory states that people associate greater psychological discomfort with losses than with gains due to loss aversion propensity. Due to advertisements that increase the urgency to buy due to the uncertainty of the item being available in the future, the consumer will rush to make a purchase before it's lost to them forever.

\section{Endowment Effect-Attachment to Possessions}

Data collected to evaluate hoarding behavior used the following independent variables related to the Endowment Effect as shown in Table 1. 
Table 1. Endowment Effect

\begin{tabular}{ll}
\hline Independent Variables & Dependent Variable \\
\hline I own possessions that express who I am & Endowment Effect \\
If I lost a possession I feel less like myself & (Difficulty discarding possessions) \\
Emotional attachment to possessions & \\
\hline
\end{tabular}

Since the Endowment Effect reveals that mere possession of an item will increase hoarding behavior, the hoarding dependent variable that was used was "difficulty discarding possessions". I predict that emotional attachment to a possession will lead to difficulty discarding a possession and the following hypothesis:

Hypothesis 1: The greater attachment to a possession with emotional value, the greater the difficulty in discarding that possession.

\section{Commodity Theory-Have a Large Percentage of Unused Items}

The key predictors of hoarding behavior that relate to the Commodity Theory from the data collected are shown in Table 2.

Table 2. Commodity Theory

\begin{tabular}{ll}
\hline Independent Variables & Dependent Variable \\
\hline Purchase items with no immediate use & Commodity Theory \\
Buy more than I need during a sale & (Large percentage of not recently used items) \\
Shortages lead to more purchases &
\end{tabular}

Scarce products or opportunities that are valued more highly cannot be passed by, even if they have no immediate use. The hoarding dependent variable was "have a large percentage of items not recently used". Since consumers tend to adopt hoarding behavior as a coping strategy during perceived scarcity conditions, I predict consumers will purchase items that have no immediate use, which led to the following hypothesis:

Hypothesis 2: The greater the perceived scarcity of an item, the greater level of acquiring a large percentage of items not recently used.

\section{Prospect Theory-Uncertainty of the Future}

Questions were asked pertaining to uncertainty of the future during the hoarding behavior study which relates to the Prospect Theory as shown in Table 3.

\section{Table 3. Prospect Theory}

\begin{tabular}{ll}
\hline Independent Variables & Dependent Variable \\
\hline Purchases due to feelings from advertisements & Prospect Theory \\
Increased urgency in ad leads to higher purchase rate & \\
Uncertainty of future leads to purchase more & (Carry just-in-case items) \\
\hline
\end{tabular}


Since the Prospect Theory explains consumer decision making under uncertainty of the future causing aversion to losing an item, the hoarding behavior dependent variable used was carry just-in-case items. I propose that urgency in advertising that portrays uncertainty of the future causes the consumer to carry just-in-case items which led to the following hypothesis:

Hypothesis 3: The greater the uncertainty of the future due to increased urgency in advertising, the greater the chance of carrying just-in-case items.

Figure 1 presents the theoretical framework for this study.

Theories DV

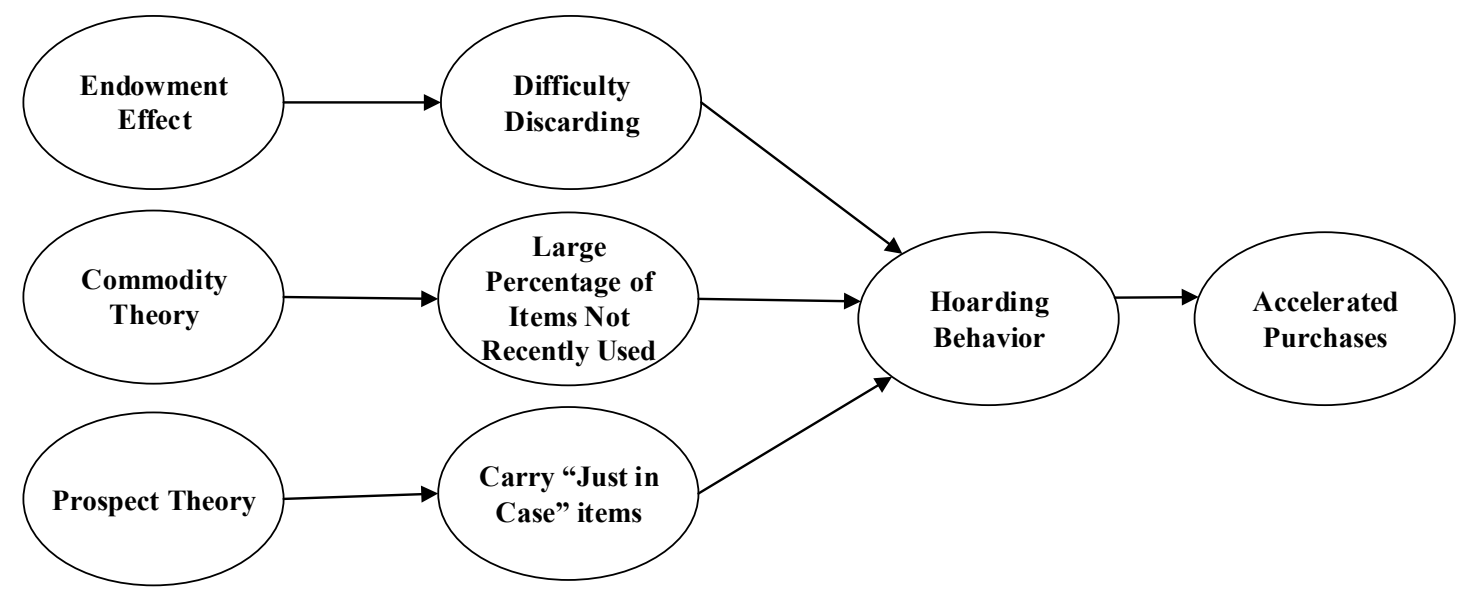

Figure 1. Theoretical Framework

\section{Methodology}

Using a descriptive research design, a primary data based quantitative study was fielded. The survey sought demographic, psychographic, attitudes, beliefs and theoretical construct information. We utilized past studies to arrive at our construct measures. An online questionnaire with four distinct categories: demographics, psychographics, lifestyle habits and attitudes towards advertising, was used. We measured the dependent variables of hoarding behaviors such as difficulty discarding possessions, having a large percentage of items not recently used, and carry just-in-case items.

The online survey method to implement the study offered several advantages. The first aspect was the respondent was able to stay anonymous, especially in light of the sensitive topic, this was crucial. Second, online survey as compared to other survey methods was more cost effective. Lastly, respondents were forced to answer every question in order to complete the survey. This was advantageous to reduce non-response bias related error. To distribute the survey we used a random sample that was then encouraged to snowball, where the survey was sent to family and friends, and passed along from there (DeMaria, King, \& Devasagayam, 2016). We used one screening question to check if the respondent was over the age of 18 prior to taking the survey.

Out of 348 respondents, 297 respondents fully completed the survey. We used structured, matrix type questions. In regards to scale measurement, we chose to use an interval 7-point Likert-type scale in order to measure absolute differences between scale points (DeMaria, King, \& Devasagayam, 2016). The two anchors ranged from 1 = "Strongly Disagree" to 7 = "Strongly Agree". Since each question was structured, the respondent had to choose from predetermined responses. The survey was kept under five minutes to reduce fatigue within the survey and in order to ensure responses in light of no incentives being offered to respondents. 
Our Sample consisted of 297 complete and usable surveys. Out of these participants, 67\% of the participants were female, while 32\% were male, the remaining $1 \%$ consisted of transgender and other identities. For data analysis, we measured the comparison between the top two genders, and removed the one percent due to insufficient responses. Just above half (53.9\%) of participants were single, where $21.1 \%$ were in a relationship; $24.9 \%$ were married (either with or without children). A majority of participants lived in a suburban area. The largest income level was less than $\$ 20,000$ with $40.1 \%$. A majority of our survey included participants with some college education and $58.6 \%$ of the sample was between the ages of 17-25 years.

Below are the original scales and the corresponding Cronbach's Alpha used from prior research as shown in Table 4.

Table 4. Cronbach's Alpha

\begin{tabular}{lll}
\hline Original Scale & Original Scale & Our Adaptation to Scale \\
\hline Psychographics & 0.80 & 0.751 \\
Possession Satisfaction & 0.80 & 0.764 \\
Attachment to Possessions & 0.80 & 0.735 \\
Compulsive Buying & 0.884 & $\mathrm{~N} / \mathrm{A}$ \\
Price Perception & $.78-.90$ & 0.747 \\
Consumer Attitudes Toward Marketing & $.69-.76$ & 0.768 \\
The Hoarding Rating Scale & $.77-.91$ & 0.735 \\
\hline
\end{tabular}

The scales consist of the Possession Satisfaction Index (Lundstrom, 1990), Possessions Attachment to Possessions (Ball \& Tasaki, 1992), Compulsive Buying Scale (Valence, d'Astous, \& Fortier, 1988), Price Perception Scale (Lichtenstein, Ridgway, \& Netemeyer, 1993), Consumer Attitudes Toward Marketing (Barksdale \& Darden, 1972), and The Hoarding Rating Scale (Tolin, Frost, \& Steketee, 2010). We also used the Big Five Factors Personality Model (Sinclair \& Barrow, 1992) and began with a bi-polar psychographics scale and felt it would be better to combine the big five with other personality traits that are predominate in hoarding such as indecisiveness, worry, risk avoidance, doubtfulness, and impulsiveness, to name a few. All our adaptations to the scales had Alpha values of 0.70 and above, indicating good internal consistency.

\section{Data Analysis and Findings}

A summary of the initial results of the data collected from the survey are in Table 5. We compared the independent variables of demographics, personality, lifestyle habits, and attitudes toward advertising against the dependent variables of three hoarding levels: difficulty discarding possessions, have a large percentage of items not recently used, and carry just-in-case items. The significance level was set at $\mathrm{p}<$ 0.10 or below and coefficient of determination (R2) was used to examine relationships between our constructs. Table 5 shows the ANOVA analysis. 
Table 5. ANOVA Analysis Results

\begin{tabular}{|c|c|c|c|c|}
\hline Independent Variables & Dependent Variable & Mean & F Value & P Value \\
\hline Uncertainty of the future leads to higher purchase & Difficulty discarding & $5.80^{\mathrm{a}}$ & 6.119 & $0.0001^{\mathrm{b}}$ \\
\hline Gender-women & possessions & 4.18 & 2.476 & 0.117 \\
\hline Gender-men & & 3.82 & 2.476 & 0.117 \\
\hline Uncertainty of the future leads to higher purchase & Large percentage of items & $5.83^{\mathrm{a}}$ & 8.416 & $0.0001^{\mathrm{b}}$ \\
\hline Gender-women & not recently used & $4.08^{\mathrm{a}}$ & 6.680 & $0.010^{\mathrm{b}}$ \\
\hline Gender-men & & $3.51^{\mathrm{a}}$ & 6.680 & $0.010^{\mathrm{b}}$ \\
\hline Uncertainty of the future leads to higher purchase & Carry just-in-case items & $6.80^{\mathrm{a}}$ & 11.195 & $0.0001^{\mathrm{b}}$ \\
\hline Gender-women & & $4.23^{\mathrm{a}}$ & 3.001 & $0.084^{\mathrm{b}}$ \\
\hline Gender-men & & $3.83^{\mathrm{a}}$ & 3.001 & $0.084^{\mathrm{b}}$ \\
\hline
\end{tabular}

a Agreement scale: a seven-point scale ranging from 7 (strongly agree) to 1 (strongly disagree);

$\mathrm{b}$ Mean difference between groups is significant at $\mathrm{p}<0.10$.

We chose to analyze the three hoarding dependent variables against the independent variable of uncertainty of the future leads to higher levels of purchasing and found there is a difference between the levels of future uncertainty based on the hoarding dependent variables. The mean difference between the groups was significant at $\mathrm{p}<0.10$ and responses show high mean values of 5.80, 5.83 and 6.80. Results indicate that consumers with high levels of hoarding behaviors who are sensitive to advertisements that portray uncertainty of future supply, or perceived shortages will have an impact on higher purchase rates. In each case, women are more likely than men to exhibit hoarding behaviors. Linear regression tests were run to further understand the relationships in the data collected and are shown in Table 6.

Table 6. Regression Analysis Results

\begin{tabular}{lllll}
\hline Confirmed Hypotheses & Dependent Variable & Sig/Direction & R2 & P Value
\end{tabular}

\begin{tabular}{lllll}
\hline $\begin{array}{l}\text { Higher levels of certain personalities } \\
\text { (composite) will lead to consumers having }\end{array}$ & $\begin{array}{l}\text { Difficulty discarding } \\
\text { possessions }\end{array}$ & 0.791 & .084 & 0.0001 \\
difficulty discarding possessions & & & & \\
$\begin{array}{l}\text { Higher levels of indecisiveness will lead to } \\
\text { consumers with a difficulty discarding }\end{array}$ & 0.396 & 0.188 & 0.0001 \\
possessions
\end{tabular}


Consumers with high levels of emotional

0.461

0.149

0.0001

attachment to possessions will have difficulty

discarding possessions

Consumer attitudes toward urgency in $\quad$ Large percentage of $\quad \begin{array}{llll}0.369 & 0.078 & 0.0001\end{array}$

advertising will lead to a large percentage of items not recently used

items not recently used

Consumer attitudes that purchases made due

0.086

0.0001

to feelings from advertisements will lead to a

large percentage of items not recently used

Consumer who have high levels of purchases

0.135

0.0001

due to shortages will have a large percentage

of items not recently used

Consumers that are uncertain of the future

Carry just-in-case items 0.485

0.177

0.0001

will have high levels of purchases and will

carry just-in-case items

We used a composite of psychographics combining the variables indecisiveness, worrisome, risk avoider, doubtful, impulsive, easily influenced by others, introverted and sensitive and found it to be significant as a composite. This led us to drill deeper into individual psychographic variables, such as indecisiveness, and found its significance at 0.0001 , a positive direction of 0.791 and a high R2 value of 0.188 . This R2 value demonstrates that $18.8 \%$ of consumers with higher levels of difficulty discarding possessions is explained by indecisiveness. This is a high number, and is similar to our literature review, where levels of indecisiveness were associated with hoarding. Indecisiveness holds the highest R2 value among all of our hypotheses above, indicating that more variance in hoarding levels is associated with indecisiveness.

We tested consumer attitudes toward urgency in advertising as well as purchases made due to feelings from advertisements against our dependent hoarding variables. We found them to be significant and positive at $0.369 \& 0.366$, but were surprised to find they had a low R2 values of 0.078 and 0.086 respectively. Between these two variables, feelings from advertisements has a larger coefficient of determination, which indicates a stronger linear relationship. Theory suggests that these variables should have a stronger relationship, and we feel further research would be helpful. Whether there was error in the wording or interpretation of the question, a deeper analysis in this area would further discover urgency in advertising's association with hoarding.

The last three hypotheses included regression results with R2 values that were relatively higher than the other hypotheses. The variables higher levels of purchases due to shortages, uncertainty of the future, and emotional attachment to possessions revealed R2 values of .135, .177, and .149 respectively. The highest, $17.7 \%$ of the variance in hoarding is associated with uncertainty of the future. Emotional attachment to possessions as well as uncertainty levels relate to prior research, and remain significant in this case. 
Aggregating results from our first study, further research using SPSS Regression Analysis was performed on the relationship that specific independent variables had to the Endowment Effect, Commodity Theory and Prospect Theory using the dependent variables difficulty discarding possessions, large percentage of unused items and carry just-in-case items. Figure 2 details the theoretical framework and the path of analysis.

IV Theories DV

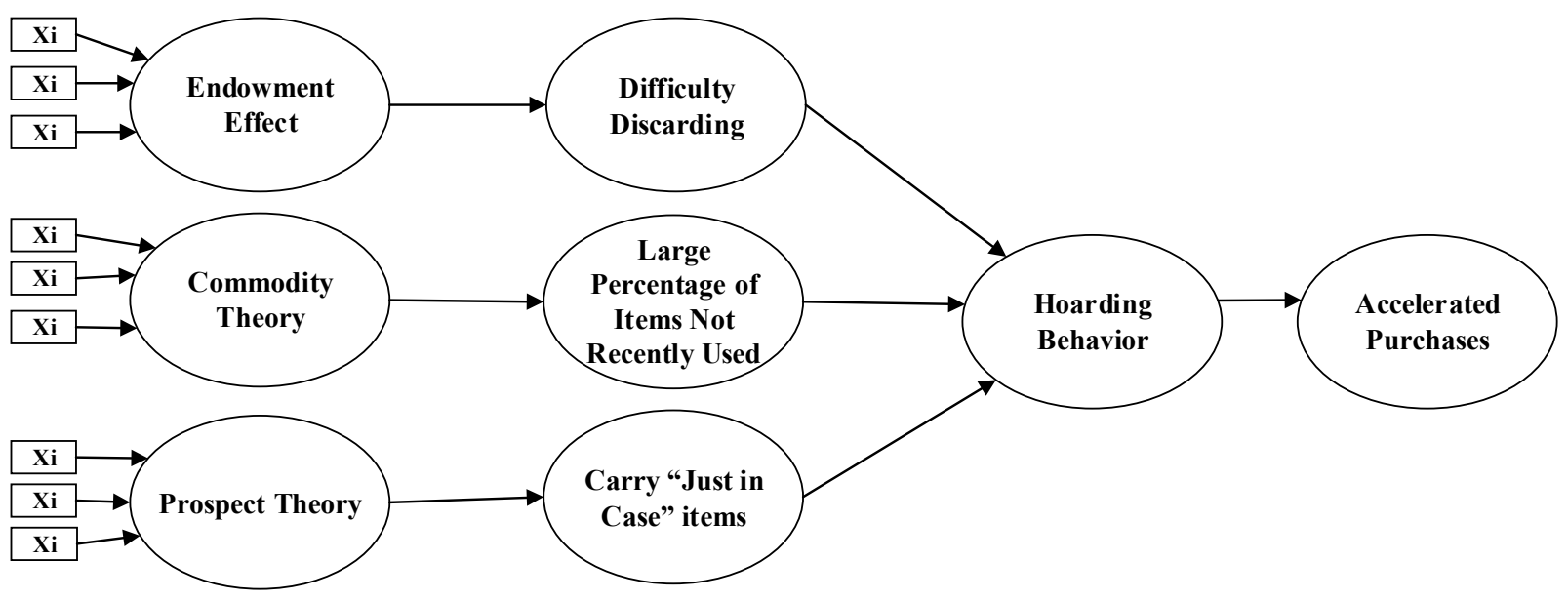

Figure 2. Theoretical Framework: Path of Analysis

Since the Endowment Effect Theory posits that mere possession of an item will increase hoarding behavior (Thaler, 1980), we ran linear regression analysis using the hoarding dependent variable difficulty discarding possessions against three independent variables individually: "I own possessions that express who I am", "If I lost a possession I feel less like myself" and "I hold an emotional attachment to some possessions". All three independent variables were significant at 0.0001 and had a positive effect on the dependent variable. It was revealed that $7.9 \%$ of consumers who have difficulty discarding possessions can be explained by the variable "I own possessions that express who I am", and $8.9 \%$ of consumers who have difficulty discarding possessions can be explained by "If I lost a possession I feel less like myself". The remaining independent variable-I hold an emotional attachment to some possessions-resulted in $14.9 \%$ of consumers with difficulty discarding possessions had an emotional attachment to possessions. As hypothesized in $\mathrm{H} 1$, the greater attachment to a possession with emotional value, the greater the difficulty in discarding that possession.

While it's hypothesized that consumers tend to adopt hoarding behavior as a coping strategy during perceived scarcity conditions, we analyzed the key predictors of hoarding related to the Commodity Theory (Brock, 1968). Since this theory states scarce products or opportunities that are valued more highly cannot be passed by, even if they have no immediate use, this led us to use the hoarding dependent variable have a large percentage of unused items individually against each of the three independent variables: "I often purchase items that have no immediate use", "I usually buy more than I need, especially during a sale", and "indicated shortages lead me to purchase more items". All independent variables were significant and had a positive effect on the dependent variable. Analysis showed that $15.4 \%$ of consumers with a large percentage of unused items can attribute it to purchasing items that have no immediate use, while $14 \%$ of consumers with a large percentage of unused items was due to purchasing more than was needed. The remaining independent variable disclosed $13.5 \%$ of 
consumers with a large percentage of unused items was attributed to "indicated shortages led them to purchase more". As hypothesized in $\mathrm{H} 2$, the greater the perceived scarcity of an item, the greater level of acquiring a large percentage of items not recently used.

As explained in the Prospect Theory (Kahneman \& Tversky, 1979), consumer decision making under conditions of increased urgency to buy due to uncertainty of an item being available in the future, the dependent variable that was used was carry just-in-case items against each of the three independent variables: "I make purchases due to feelings from advertisements", "increased urgency in an ad leads me to purchase more items", and "uncertainty of the future leads me to purchase more items". All independent variables were significant and had a positive effect on the dependent variable. Analysis showed $2.2 \%$ of consumers that carry just-in-case items are attributed to making purchases due to feelings from advertisements, while $4.4 \%$ of consumers who carry just-in-case items are due to increased urgency in an ad that leads them to purchase more. The last independent variable revealed that $17.7 \%$ of consumers who carry just-in-case items are due to uncertainty of the future leads to a higher purchase rate. As hypothesized in H3, the greater the "uncertainty of the future due to increased urgency in advertising", the greater the chance of carrying just-in-case items.

When we ran a composite of the three independent variables associated with each dependent variable the results were open to interpretation due to multicollinearity, which we did not report. Table 7 below details regression analysis results of each independent variable to its respective dependent variable.

Table 7. Regression Analysis Results

\begin{tabular}{lllll}
\hline Independent Variable & Dependent Variable & Sig/Direction & $\mathrm{R}^{2}$ & P Value \\
\hline I own possessions that express who I am & Endowment Effect & 0.326 & 0.079 & 0.0001 \\
If I lost a possession I feel less like myself & (Difficulty discarding & 0.326 & 0.089 & 0.0001 \\
Emotional attachment to possessions & possessions) & 0.461 & 0.149 & 0.0001 \\
Purchase items with no immediate use & Commodity Theory & 0.378 & 0.154 & 0.0001 \\
Buy more than I need during a sale & (Large percentage of not & 0.339 & 0.14 & 0.0001 \\
Shortages lead to more purchases & recently used items) & 0.39 & 0.135 & 0.0001 \\
Purchases due to feelings from & Prospect Theory & 0.189 & 0.022 & 0.0111 \\
Increased urgency in ad leads to buy more & (Carry just-in case items) & 0.285 & 0.044 & 0.0001 \\
Uncertainty of future leads to purchase more & & 0.485 & 0.177 & 0.0001 \\
\hline
\end{tabular}

\section{Managerial Implications, Limitations, and Future Research}

To be successful in the retail environment, marketing managers should develop strategies that stimulate positive emotional or behavioral reactions from shoppers (Babin \& Darden, 1996). The findings of our study provide insights into behavioral responses to the strategies of perceived scarcity and perceived perishability of consumer goods that provoke hoarding behavior resulting in increased purchase rates. Our findings show that under uncertainty of future availability conditions, consumers exhibit an emotional attachment to possessing an item which triggers a feeling of loss aversion prompting an immediate decision to purchase the valued item. This explains why consumers exhibiting hoarding behavior have difficulty discarding items once an emotional attachment to an item has been established. 
Additionally, marketing managers that frame perceived perishability or scarcity of items with urgency for immediate action through advertising will intensify the reaction of loss aversion and motivate the consumer to buy before the opportunity is lost to them. This research can help marketing manager's acquire more knowledge of internal purchase motives such as emotional attachment satisfaction or feelings of uniqueness gained through purchasing limited quantity products that are valued. Furthermore, once an understanding of what motivates consumers to accelerate their purchase behavior under perceived perishability and scarcity conditions is obtained, pricing and inventory strategies can be designed to meet the needs of the customer.

The question that should be asked is whether this method of consumer marketing is ethical? As further research continues in the area of perceived shortages and perishability of products, ethical decision-making should be considered as the marketing manager intends to illicit in-store hoarding through urgency in advertising.

One of the critical limitations of the initial study was $58.6 \%$ of the sample was between the ages of 17-25 years old due to the researcher's affiliation with a College. We also had a limited timeframe to conduct the survey, resulting in a smaller pool of respondents. Further research is suggested to find additional conditions other than perceived scarcity and perishability that would result in accelerated purchase behaviors. In our research we focused on individual hoarding behaviors and internal emotional responses, but future research can be undertaken to study the effect of external stimuli on hoarding behavior, such as influences from social groups, consumer opinions, and online reviews. Another area of future research would be to understand hoarding behaviors in cross-cultural and cross-national settings.

\section{References}

Babin, B. J., \& Darden, W. R. (1996). Good and bad shopping vibes: Spending and patronage satisfaction. Journal of Business Research, 35(3), 201-206. https://doi.org/10.1016/0148-2963(95)00125-5

Bearden, W. O., \& Netemeyer, R. G. (1999). Handbook of marketing scales: Multi-item measures for marketing and consumer behavior research. Thousand Oaks, CA: Sage Publications. https://doi.org/10.4135/9781412984379

Brock, T. C. (1968). Implications of commodity theory for value change. New York: Academic Press. https://doi.org/10.1016/b978-1-4832-3071-9.50016-7

Bulow, J. (1986). An economic theory of planned obsolescence. The Quarterly Journal of Economics, 101(4), 729. https://doi.org/10.2307/1884176

Byun, S. E., \& Sternquist, B. (2008). In-store hoarding: The measurement and application in the fast fashion retail environment. The International Review of Retail, Distribution and Consumer Research, 18(2), 133-147. https://doi.org/10.1080/09593960701868241

Byun, S. E., \& Sternquist, B. (2012). Here today, gone tomorrow: Consumer reactions to perceived limited availability. Journal of Marketing Theory and Practice, 20(2), 223-234. https://doi.org/10.2753/MTP1069-6679200207

Canale, A., \& Klontz, B. (2013). Hoarding disorder: It's more than just an obsession-Implications for financial therapists and planners. Journal of Financial Therapy, 4(2), 42-63. https://doi.org/10.4148/1944-9771.1053 
Cherrier, H., \& Ponnor, T. (2010). A study of hoarding behavior and attachment to material possessions. Qualitative Market Research: An International Journal, 13(1), 8-23. https://doi.org/10.1108/13522751011013945

Coles, M. E., Frost, R. O., Heimberg, R. G., \& Steketee, G. (2003). Hoarding behaviors in a large college sample. Behaviour Research and Therapy, 41(2), 179-194. https://doi.org/10.1016/S0005-7967(01)00136-X

DeMaria, J., King, D., \& Devasagayam, R. (2016). Antecedents of hoarding behavior: A marketing perspective. International Journal of Academic Research in Business and Social Sciences, 6(9), 384-398. https://doi.org/10.6007/IJARBSS/v6-i9/2332

Frost, R. O., \& Gross, R. C. (1993). The hoarding of possessions. Behaviour Research and Therapy, 31(4), 367-381. https://doi.org/10.1016/0005-7967(93)90094-B

Frost, R. O., Hartl, T. L., Christian, R., \& Williams, N. (1995). The value of possessions in compulsive hoarding: Patterns of use and attachment. Behavior Research Therapy, 33(8), 897-902. https://doi.org/10.1016/0005-7967(95)00043-W

Kahneman, D., \& Tversky, A. (1979). Prospect theory: An analysis of decision under risk. Econometrica, 47(2), 263. https://doi.org/10.2307/1914185

Lynn, M. (1991). Scarcity effects on value: A quantitative review of the commodity theory literature. Psychology \& Marketing, 8(1), 43-57. https://doi.org/10.1002/mar.4220080105

McKinnon, G., Smith, M. E., \& Hunt, H. K. (1985). Hoarding behavior among consumers: Conceptualization and marketing implications. Journal of the Academy of Marketing Science, 13(1-2), 340-351. https://doi.org/10.1007/BF02729724

Sternquist, B. (2007). International Retailing. New York: Fairchild.

Still, R., Johnson, K., \& Tourk, K. A. (1975). Scarcity and hoarding: Economic and social explanations and marketing implications. Association for Consumer Research, 203-216.

Thaler, R. (1980). Toward a positive theory of consumer choice. Journal of Economic Behavior \& Organization, 1(1), 39-60. https://doi.org/10.1016/0167-2681(80)90051-7 